\title{
Comparison of Different Strategies for Providing Fecal Microbiota Transplantation to Treat Patients with Recurrent Clostridium difficile Infection in Two English Hospitals: A Review
}

\author{
Simon D. Goldenberg (D) - Rahul Batra • Ian Beales • \\ Jonathan Leith Digby-Bell • Peter Miles Irving • Lee Kellingray • \\ Arjan Narbad $\cdot$ Ngozi Franslem-Elumogo
}

Received: January 3, 2018 / Published online: February 15, 2018

(C) The Author(s) 2018. This article is an open access publication

\section{ABSTRACT}

Fecal microbiota transplant (FMT) has emerged as a highly efficacious treatment for difficult cases of refractory and/or recurrent Clostridium difficile infection (CDI). There have been many well-conducted randomized controlled trials and thousands of patients reported in case series that describe success rates of approximately $90 \%$ following one or more FMT. Although the

Enhanced content To view enhanced content for this article go to https://doi.org/10.6084/m9.figshare. 5844840 .

S. D. Goldenberg $(\square) \cdot$ R. Batra

Centre for Clinical Infection and Diagnostics Research (CIDR), King's College London and Guy's and St. Thomas' NHS Foundation Trust, London, UK e-mail: Simon.goldenberg@gstt.nhs.uk

I. Beales

Department of Gastroenterology, Norfolk and Norwich University Hospitals NHS Foundation Trust, Norwich, UK

J. L. Digby-Bell · P. M. Irving

Department of Gastroenterology, Guy's and St.

Thomas' NHS Foundation Trust, London, UK

L. Kellingray · A. Narbad

Quadram Institute Bioscience, Norwich Research

Park, Norwich, UK

N. Franslem-Elumogo

Department of Medical Microbiology, Eastern

Pathology Alliance, Norfolk and Norwich University

Hospitals NHS Foundation Trust, Norwich, UK exact mechanisms of FMT have yet to be fully elucidated, replacement or restoration of a 'normal' microbiota (or at least a microbiota resembling those who have never had CDI) appears to have a positive effect on the gut dysbiosis that is thought to exist in these patients. Furthermore, despite being aesthetically unappealing, this 'ultimate probiotic' is a particularly attractive solution to a difficult problem that avoids repeated courses of antibiotics. The lack of clarity about the exact mechanism of action and the 'active ingredient' of FMT (e.g., individual or communities of bacteria, bacteriophage, or bioactive molecules such as bile acids) has hindered the ability to produce a standardized and well-characterized FMT product. There is no standard method to produce material for FMT, and there are a multitude of factors that can vary between institutions that offer this therapy. Only a few studies have directly compared clinical efficacy in groups of patients who have been treated with FMT prepared differently (e.g., fresh vs. frozen) or administered by different route (e.g., by nasojejunal tube, colonoscopy or by oral administration of encapsulated product). More of these studies should be undertaken to clarify the superiority or otherwise of these variables. This review describes the methods and protocols that two English NHS hospitals independently adopted over the same time period to provide FMT for patients with recurrent CDI. There are several fundamental differences in the 
methods used, including selection and testing of donors, procedures for preparation and storage of material, and route of administration. These methods are described in detail in this review highlighting differing practice. Despite these significant methodological variations, clinical outcomes in terms of cure rate appear to be remarkably similar for both FMT providers. Although both hospitals have treated only modest numbers of patients, these findings suggest that many of the described differences may not be critical factors in influencing the success of the procedure. As FMT is increasingly being proposed for a number of conditions other than CDI, harmonization of methods and techniques may be more critical to the success of FMT, and thus it will be important to standardize these as far as practically possible.

Keywords: Clostridium difficile; Dysbiosis; Fecal microbiota transplantation; Gut microbiome; Microbiota replacement therapies; Stool bank

\section{INTRODUCTION}

Since the publication of a number of randomized controlled trials demonstrating its efficacy in treating recurrent Clostridium difficile Infection (rCDI) [1-8], and subsequent National Institute for Health and Care Excellence (NICE) Interventional Procedure Guideline IPG485 [9], fecal microbiota transplantation (FMT) has increasingly been adopted by some healthcare centers as a valuable management option in this difficult-to-treat patient group. A national survey conducted in 130 sites in the UK in 2015 found that $36(28 \%)$ of centers had performed at least one FMT [10].

Up to $25 \%$ of patients treated with metronidazole or vancomycin will suffer a recurrence within 30 days [11-13], and approximately $45-65 \%$ of these will have a second recurrence $[14,15]$. Rates of recurrence have recently increased, potentially related to the spread of the epidemic BI/NAP1 027 strain [16]. The introduction of newer therapies such as fidaxomicin [11, 12, 17-19] and bezlotoxumab $[20,21]$ have been shown to significantly reduce the risk of recurrence; however, there are a number of patients whose microbiome is seemingly disrupted to such an extent that the most effective management is the restoration of a healthier microbiota through FMT [22].

Prior randomized controlled studies demonstrated the efficacy and short-term safety of FMT [1-8], with a corresponding increase in published studies and interest amongst both clinicians and patients [23].

A number of national and international guidelines now include FMT as a treatment option (usually following a second or further recurrence) after failure with standard anti- $C$. difficile antibiotics [9, 24-28]. In addition, there are at least two sets of consensus recommendations based on literature review and agreement using Delphi methodology by experts in the field $[29,30]$.

Despite this, there are limited data comparing practice across a range of factors, such as donor selection and testing, preparation and storage of material, and route of administration of FMT. Consequently, in clinical practice, FMT methods and protocols are unstandardized, with individual centers developing their own local policies and procedures based on their own experience.

We aimed to describe the practical use of FMT to treat patients with rCDI at two NHS hospitals in England. Both hospitals independently chose to undertake FMT using significantly different methods and procedures. We examine the key differences in these two providers and compare outcomes in terms of clinical success and adverse events.

\section{Compliance with Ethics Guidelines}

This article is based on previously conducted studies and does not contain any studies with human participants or animals performed by any of the authors.

\section{Setting}

FMT was adopted for use in patients with rCDI at two English National Health Service (NHS) hospitals: Guy's and St Thomas' NHS 
Foundation Trust in London, and Norfolk and Norwich University Hospitals NHS Foundation Trust. Both hospitals introduced FMT in 2014.

Guy's and St. Thomas' Hospitals (provider A) is a secondary and tertiary academic center with 1100 beds providing 2.4 million patient contacts (daycase, inpatient and outpatient) per year. Norfolk and Norwich University Hospitals (provider B) is a 1000-bed acute secondary and tertiary care hospital providing 1 million patient contacts per year. Both providers have comprehensive microbiology, infection control, and gastroenterology services.

\section{Indications and Exclusions for FMT}

Indications for FMT in provider A are rCDI (at least three distinct episodes) that have been treated with standard anti-C. difficile antibiotics, including either fidaxomicin or pulsed/tapered vancomycin. A second indication is in severe or fulminant CDI as an adjunct to either fidaxomicin or vancomycin that has failed to achieve sufficient clinical response after 5 days of therapy.

Indications in provider B are rCDI (three episodes or more as judged by a multi-disciplinary team comprising a microbiologist and gastroenterologist) with no requirement for specific antibiotic treatment. FMT is also offered to selected patients after the first recurrence (second episode) if there are other complicating co-morbidities (e.g., diabetes mellitus, chronic renal failure, etc.), justified indications for ongoing or recurrent concomitant antibiotics, or severe disease.

There are three main contraindications to FMT at provider A, which are all relative. (1) Major immunosuppressive state [(high-dose steroids equivalent to $>60 \mathrm{mg}$ prednisolone/day, mechanistic target of rapamycin (mTOR) inhibitors, lymphocyte-depleting agents, anti-TNF agents, other chemotherapeutic antineoplastic agents within the last 6 weeks, advanced HIV/AIDS with CD4 <240, bone marrow transplant, solid organ transplant recipient); (2) decompensated liver disease; and (3) life-threatening food allergies, e.g., nuts, etc.
Provider A does not have any age exclusions and treats children.

Provider B has only one absolute exclusion criterion which is children under the age of 16 years. Relative exclusions include severe colitis warranting intensive care admission, toxic megacolon and concurrent non-C. difficile broad-spectrum antibiotics.

\section{Donor Selection and Screening}

Both providers use mainly unrelated donors who are anonymous to the recipient. Both providers have accommodated requests to perform donor-directed procedures (using either related household members or friends of the recipient); however, for logistical reasons, anonymous donors are preferred.

Provider A uses a mixture of hospital employees (and partners/friends of hospital employees) who are almost exclusively nonclinical, together with a number of donors from the general public (who are healthy but have been previous patients at the hospital).

Provider B excludes clinical staff from being donors and uses mainly research staff and scientists (non-clinical, research staff) as donors.

Neither provider financially compensates donors for their time. This approach was adopted in line with standard practice for blood donation and is in accordance with the World Health Organizations Melbourne Declaration on voluntary, non-remunerated donation [31].

Provider A uses a detailed questionnaire as a screening tool which is completed in conjunction with a microbiologist or infectious diseases physician assessment. Table 1 lists factors which would preclude donation. If the material is to be used in those born after 1997, a donor who did not live in the UK prior to 1996 is used to minimize the risk of transmission of CJD/vCJD.

Provider B uses a previously published donor screening questionnaire administered by the recruiting microbiologist after extensive discussions with the potential donor [32]. This is very similar to that used by provider $A$, but does not have any restrictions regarding age, body mass index or receipt of oral medications. The potential donor is given written information 
Table 1 Criteria for selecting an FMT donor

Factors which preclude donation include

Age under 18 or over 60

Body mass index over 25

Currently taking any prescribed oral medications

Known to be infected with $\mathrm{HIV} / \mathrm{HTLV} / \mathrm{Hepatitis} \mathrm{A} / \mathrm{B} / \mathrm{C} / \mathrm{E}$; active EBV or CMV

Active diarrhea (defined as three or more unformed bowel movements for at least 2 consecutive days)

High-risk sexual behavior, including sexual intercourse with those known to have HIV or hepatitis, sexual intercourse with commercial sex workers, and men who have sex with men, unless they have abstained from sex for the past 3 months

Use of recreational drugs

Tattoos or body piercings within the last 6 months

History of being in prison anytime in the last 12 months

Inflammatory bowel disease, irritable bowel syndrome, gastrointestinal malignancy or polyps, any other gastrointestinal disorder, previous gastrointestinal surgery

Metabolic syndrome, diabetes, any systemic autoimmune disease, e.g., multiple sclerosis, connective tissue disorder

Use of systemic antibiotics within the past 3 months

Colonization with antibiotic-resistant bacteria (MRSA/VRE/CRO)

Major immunosuppressive agents

Atopy including eczema and asthma

Chronic pain syndromes, e.g., chronic fatigue, fibromyalgia

about the donor screening process, screening frequency and consent forms to take away to read, and another appointment is made to proceed when they are ready and all questions have been satisfactorily answered.

\section{Donor Testing}

Provider A tests donors who do not fall into any of the aforementioned exclusion criteria using serology and stool testing. Serology tests include HIV 1+2 antigen/antibodies, HTLV I/II antibodies, hepatitis A IgM, hepatitis B surface antigen and core antibody, hepatitis E IgG and IgM, Treponema palladium antibodies, Cytomegalovirus IgM, Epstein Barr Virus IgG and IgM, Strongyloides ELISA. Provider B performs the same tests but also includes serology for Helicobacter pylori and Entamoeba histolytica.
Provider A tests stool samples for the following: multiplex PCR for Campylobacter, Salmonella, Shigella and Verocytotoxin producing E. coli; concentration and microscopy for ova, cysts and parasites, GDH, toxin A/B EIA and PCR for Clostridium difficile, norovirus PCR, antigen for Helicobacter pylori, Entamoeba histolytica PCR, resistant Gram-negative organism culture, methicillin-resistant Staphylococcus aureus (MRSA) culture. Provider A has used a total of 8 different donors to date and has excluded 10 on the basis of risk factors or positive test results.

Provider B tests stool for Campylobacter, Salmonella, Shigella and E. coli O:157 using culture. Tests for $C$. difficile include GDH and toxin A/B EIA. Provider B screens for multi-drug-resistant pathogens including MRSA, extended spectrum beta-lactamase-producing organisms (ESBLs), 
carbapenemase-producing enterobacteriaceae (CPE) and vancomycin-resistant enterococci (VRE). All other stool testing is the same as described for provider A. To date, 6 donors have expressed interest of which 4 have been screened and 3 of these have donated. There has been one occasion where a donor could not donate due to recent upper respiratory tract infection and another where the donor had recent antibiotics. So far, all 4 donors who have undergone microbiological testing have passed.

In addition to initial donor testing, all accepted donations at provider A are further tested for Campylobacter, Salmonella, Shigella, verocytotoxin producing $E$. coli, norovirus, $C$. difficile and parasites, using the methods described above. All serological testing and resistant bacteria stool testing are repeated at 3 -monthly intervals. Provider B recalls donors for repeat microbiological tests every 6 months.

Both providers use a secondary questionnaire for each occasion the volunteer donates. This asks about symptoms and risk factors which have emerged between the date of initial questionnaire completion and time of donation. This includes diarrhea and vomiting, fever, jaundice, lymphadenopathy, sore throat, use of antibiotics, travel outside the UK, intravenous drug use and new sexual partners. If the donor reports any of these symptoms or risk factors, he/she may be excluded from donating (either permanently or for a minimum of 3 weeks before undergoing a full set of laboratory tests as described above).

\section{Preparation of Material for FMT}

Material is processed within $6 \mathrm{~h}$ of donor production (however, this is nearly always achieved within $2 \mathrm{~h}$ ) at provider A. Material is processed in a class II biosafety cabinet using ambient air. Between 50 and $100 \mathrm{~g}$ of stool is mixed with approximately $150 \mathrm{~mL}$ of sterile $0.9 \%$ sodium chloride. This is mixed using a food grade disposable mixer of the type used to prepare protein drinks. Once homogenized, the mixture is poured through a disposable kitchen-grade nylon sieve to remove large particles. Further $0.9 \%$ saline and $12.5 \%$ glycerol (as a cryopreservant) are added to achieve a final volume of $250 \mathrm{~mL}$ for colonoscopic administration (or $150 \mathrm{~mL}$ if using the nasojejunal route).

Provider B uses approximately $80 \mathrm{~g}$ of stool which is added to a stomacher bag with $400 \mathrm{~mL}$ sterile $0.9 \%$ sodium chloride. This is homogenized for $1 \mathrm{~min}$ in the stomacher at $230 \mathrm{rpm}$. The resulting slurry is filtered, decanted and stored in seven 60 -mL capped oral syringes (final volume of $420 \mathrm{~mL}$ ) for nasojejunal administration within $4 \mathrm{~h}$ of production.

\section{Storage of FMT Material}

At provider A, material for FMT is labeled and stored frozen at $-80{ }^{\circ} \mathrm{C}$ until required. Banked material is stored for a maximum of 6 months before being discarded as clinical waste. Refreezing once defrosted is not permitted. There are several in vitro and clinical studies supporting the stability of material for FMT when stored in these conditions $[3,6,8,33-35]$. Provider $\mathrm{B}$ uses freshly prepared material which is used within $4 \mathrm{~h}$ of preparation or otherwise discarded as clinical waste. Both providers archive aliquots of donation material indefinitely at $-80^{\circ} \mathrm{C}$ in the event that these need further testing, e.g., in the case of an adverse event or as part of a look-back investigation.

\section{Identification of Recipients and Method of FMT Administration}

Referrals (internal or external) at provider A are made either to the microbiology or gastroenterology department who assess the patient for eligibility. The service is provided jointly by the departments of microbiology and gastroenterology either on an inpatient or outpatient basis. Provider A primarily administers FMT by colonoscope, but has occasionally administered using a nasojejunal tube. The procedure is undertaken in the endoscopy suite at the end of a routine list to allow enhanced environmental cleaning following the procedure.

Provider B identifies potential patients using laboratory data and during weekly multi- 
disciplinary $C$. diffiicile ward rounds. The primary route of delivery for hospital $B$ is via nasojejunal tube and occasionally via sigmoidoscopy when a nasojejunal tube cannot be tolerated. This is performed at the patient bedside in an isolation room with bathroom facilities or in the endoscopy suite if carried out as an outpatient or via a sigmoidoscopy route.

There are a number of studies that have used various methods of administration which include an upper gastrointestinal route (via nasogastric, nasojejunal or nasoduodenal tube), lower gastrointestinal (via retention enema or colonoscopy) or using capsules (either fresh frozen or lyophilized). One randomized study comparing upper and lower GI administration found a non-significantly higher cure rate with colonoscopy; however, this was a pilot study with only five and six patients in each arm [8].

Another randomized controlled trial comparing capsules with FMT by colonoscopy reported no difference in overall cure rates [4]. However, other studies including four metaanalyses have suggested that colonoscopic administration has better cure rates than the upper GI route [36-39]. Additionally, a large case series of 2050 patients has demonstrated that FMT by colonoscopy ( $85.8 \%$ clinical cure, $n=1441)$ was superior to upper endoscopy (74.1\% clinical cure, $n=201)(P<0.01)$ [40].

\section{Recipient Preparation}

Provider A administers a minimum of 5 days' pre-treatment with either vancomycin $125 \mathrm{mg}$ four times/day (unless on a tapering course) or fidaxomicin $200 \mathrm{mg}$ twice daily. This is discontinued 2 days prior to the procedure.

Bowel preparation is given as per normal protocol for diagnostic colonoscopy using macrogol (Moviprep ${ }^{\circledR}$ ) along with standard precolonoscopy dietary recommendations of no solid foods for $24 \mathrm{~h}$. Then, $8 \mathrm{mg}$ of loperamide is administered orally pre-procedure to aid retention of transplant material. For colonoscopically administered FMT, conscious sedation with fentanyl and midazolam is administered as per routine colonoscopy. On insertion of the colonoscope, an effort is made to use minimal air insufflation and suction of fluid pools is performed. The FMT material is drawn up into multiple 50-ml 'slip tip' syringes and pushed rapidly down the biopsy channel of the colonoscope into the cecum (or administered as proximally as possible if unable to reach the cecum), followed by $20 \mathrm{ml}$ of saline.

For nasojejunal delivery, a proton pump inhibitor (e.g., omeprazole $20 \mathrm{mg}$ twice daily) is administered for 2 days prior to the FMT. On the day of the FMT, a nasojejunal tube with a minimum gauge of $9 \mathrm{Fr}$ (as smaller diameter tubes tend to block and require force to instill due to the viscosity of the material) is inserted in endoscopy. The patient is then turned onto their back and sat up on the trolley. The FMT is drawn into 20-ml Luer lock feeding syringes and instilled slowly at $10 \mathrm{ml} / \mathrm{min}$. The patient is carefully observed for signs of coughing or vomiting and, if detected, the infusion aborted.

Provider B recommends a minimum of 4 days of vancomycin $500 \mathrm{mg}$ four times per day (stopping the evening before the procedure) prior to the FMT. Provider B initially used bowel prep with a macrogol-containing solution the day before the procedure as per the manufacturer's instructions or until bowel motions become watery and clear. Subsequently, bowel lavage was discontinued due to lack of strong evidence of effectiveness [40]. Patients are fasted overnight but permitted to take sips of water or fruit juice up to $1 \mathrm{~h}$ prior to the procedure. No gastric acid-suppressing agent is used.

Both providers offer an information leaflet which is given to the patient, and they are consented for the procedure as per usual clinical practice.

\section{Immediate Recovery and Monitoring}

Immediate recovery and monitoring are the same as for a diagnostic colonoscopy at provider A. For colonoscopic administration, patients are warned that they are likely to experience some diarrhea immediately following the procedure. The patient may be discharged once sufficiently recovered later the same day and can eat and drink on discharge. For nasojejunal administration, the tube is removed immediately after 
administration. The patient is advised to maintain an upright position for a minimum of $2 \mathrm{~h}$ after which time they can eat and drink as normal.

Provider B monitors for a short time period (until first bowel movement) and allows fluids $1 \mathrm{~h}$ after the procedure. The nasojejunal tube is removed $30-60 \mathrm{~min}$ after the procedure [41].

\section{Patient Follow Up and Criteria for Success}

Patients at provider A are offered a gastroenterology outpatient clinic appointment after 2 months. If the patient declines or fails to attend (or if they do not live in the local area), a follow-up appointment is undertaken by telephone. Clinical cure is defined as resolution of diarrhea with no further requirement for anti- $C$. difficile treatment at 8 weeks or more following FMT. Stool samples are not routinely taken for C. difficile testing providing clinical cure is achieved. Recurrence is defined as return or ongoing diarrhea with positive stool test for $C$. difficile (GDH antigen plus toxin A/B EIA and PCR for toxin gene).

Hospital B follows patients up for as long as they remain an inpatient, and encourages patients to contact their clinical team in the event of a possible recurrence.

\section{Governance Arrangements, Reporting and Investigation of Adverse Events}

Both providers have a clinical guideline which sets out criteria for FMT and any contraindications. This is approved by the hospital Clinical Governance Committee and Drugs and Therapeutic Committee. In addition, a Standard Operating Procedure is used to ensure consistency in processing, storage and preparation of material. Although FMT in the UK is not regulated by the Human Tissue Authority, the standards outlined in the Human Tissue Act 2004, the Human Tissue (Quality and Safety for Human Application) Regulations 2007 [42] and the HTA's Codes of Practice [43] are followed as far as is practically possible. In particular, there are procedures to ensure that donor and recipient documentation is collected and maintained to ensure traceability.

\section{Outcomes}

To date (September 2017), a total of 36 patients have been treated by provider A. Patients had a mean age of 75 years with a range of 4-92. Two children aged 4 and 15 have also been treated. Three patients had FMT via nasojejunal tube, one via a loop ilesotomy and the remainder by colonoscopy. Two patients had a laboratoryconfirmed recurrence (both after at least 4 months of being symptom-free, and both after taking further courses of antibiotics). We did not observe any short-term adverse events directly related to the FMT; however, there were two patient deaths within 3 months of FMT, neither of which were determined to be directly related to FMT.

Hospital B has conducted 27 procedures in 26 patients with a mean age of 72 years (range 41-91). One patient has received FMT twice due to a further relapse after 3 months. A total of 24 procedures were via nasojejunal tube and 2 via sigmoidoscopy. The majority of patients did not have any significant adverse events. However, one 81-year-old patient had an episode of vomiting immediately following nasojejunal administration of FMT. The patient subsequently developed an aspiration pneumonia and died 10 days later. This was thought to be as a result of the FMT procedure at provider B, and a similar case has been previously reported [44].

There is a general lack of long-term safety data in the literature, with most studies following patients for a mean of between 3 and 24 months [45]. One systematic review of 18 observational studies involving 611 patients reported 38 deaths, 6 of which were associated with relapsed or severe CDI and 3 with other infectious diseases such as pneumonia and peritonitis [45]. A larger review including 109 publications and 1555 patients reported 3 deaths potentially attributable to FMT [46].

Other commonly reported adverse events include diarrhea, bloating, flatulence and abdominal pain/cramping, which are almost always mild-moderate and self-limiting [45-47]. 


\section{DISCUSSION}

There were several significant differences in the methods and procedures used in administering FMT to patients with rCDI in these two healthcare providers, which are summarised in Table 2. This is perhaps not surprising since there are very few data demonstrating superiority of any one method or protocol. Centers have adopted different practices according to evidence available at the time, iteratively adapting their protocols when the need arises. In the absence of well-conducted studies to determine optimal methods and procedures, centers are likely to continue using approaches that are already in place or are convenient to the patient and/or clinician.

There are a number of European consensus documents which attempt to address key issues; however, a significant proportion of recommendations are based only on expert opinion $[26,29,30]$. For example, of the 28 statements in the European consensus document, 19 (68\%) have only weak supporting evidence, 5 (18\%) moderate supporting evidence and only 4 (14\%) have strong evidence [29]. This lack of clear evidence-based guidelines has been suggested as a barrier to the more widespread adoption of FMT as a treatment modality in the UK and other countries [48-50].

One of the most fundamental sources of variation is the route of FMT administration. One systematic review which compared various routes of administration included a total of 182 patients (148 received FMT via colonoscopy and 34 received FMT via nasogastric tube) from 12 published studies [51]. Recurrence of CDI after FMT was similar in both the colonoscopy group $(8 / 148,5.4 \%)$ versus the NGT group $(2 / 34$, $5.9 \%)(P=1.000)$. However, the overall rate of cure after FMT was slightly higher in patients receiving FMT by colonoscopy: 85.3\% (29 patients, 29/34) in the nasogastric tube group and $93.2 \%$ (138 patients, 138/148) in the colonoscopy group $(P=0.162)$. A larger and more recent systematic review of 14 studies including 305 patients comparing FMT delivery by upper and lower gastrointestinal routes also favored lower gastrointestinal delivery [52]. At 30 and
90 days, the risk of clinical failure was 5.6 and $17.9 \%$ in the upper gastrointestinal group compared with 4.9 and $8.5 \%$ in the LGI delivery route group, respectively. Expert consensus opinion does not provide a preference for the route of administration in terms of efficacy, but notes that lower gastrointestinal administration may be associated with fewer adverse events [30]. More recently, encapsulated preparations of FMT have been used with success [4, 53-57]. This route has the advantage of being less invasive and simpler, which may also result in improved cost-effectiveness. However, colonoscopic administration also allows for identification of alternative diagnoses.

The source and screening of donors, the amount of stool used and the processing of FMT preparations, storage and use of product (fresh or frozen), and several other factors have all being described in varying ways in the current literature. However, there is a lack of evidence to suggest superiority of many of these variables.

The period of time following discontinuation of anti-C. difficile antibiotics and FMT procedure would seem to be a critical variable to ensure that transplanted material is not deleteriously damaged by any residual antibiotic in the gastrointestinal tract. Studies report a washout period ranging from 1 to 3 days $[4,6,7,47,58-70]$.

One study has demonstrated that vancomycin remains detectable in feces for 4-5 days after discontinuation of therapy [71], which could potentially and significantly impact the success of the procedure. However, the cited report did not study patients who had been given bowel preparation, which presumably would reduce the remaining concentration of antibiotic, so limiting its effect on the FMT material.

Based on our clinical experience so far, this heterogeneity does not appear to materially affect clinical outcomes. Remarkably, nearly all patients who have received FMT in our centers have responded favorably (100\% success rate at 4 months and $94 \%$ overall success rate for provider $A$ and $96 \%$ after one treatment for provider B). This suggests that these variables have limited or no influence on clinical outcomes. 
Table 2 Main differences in practice at each provider

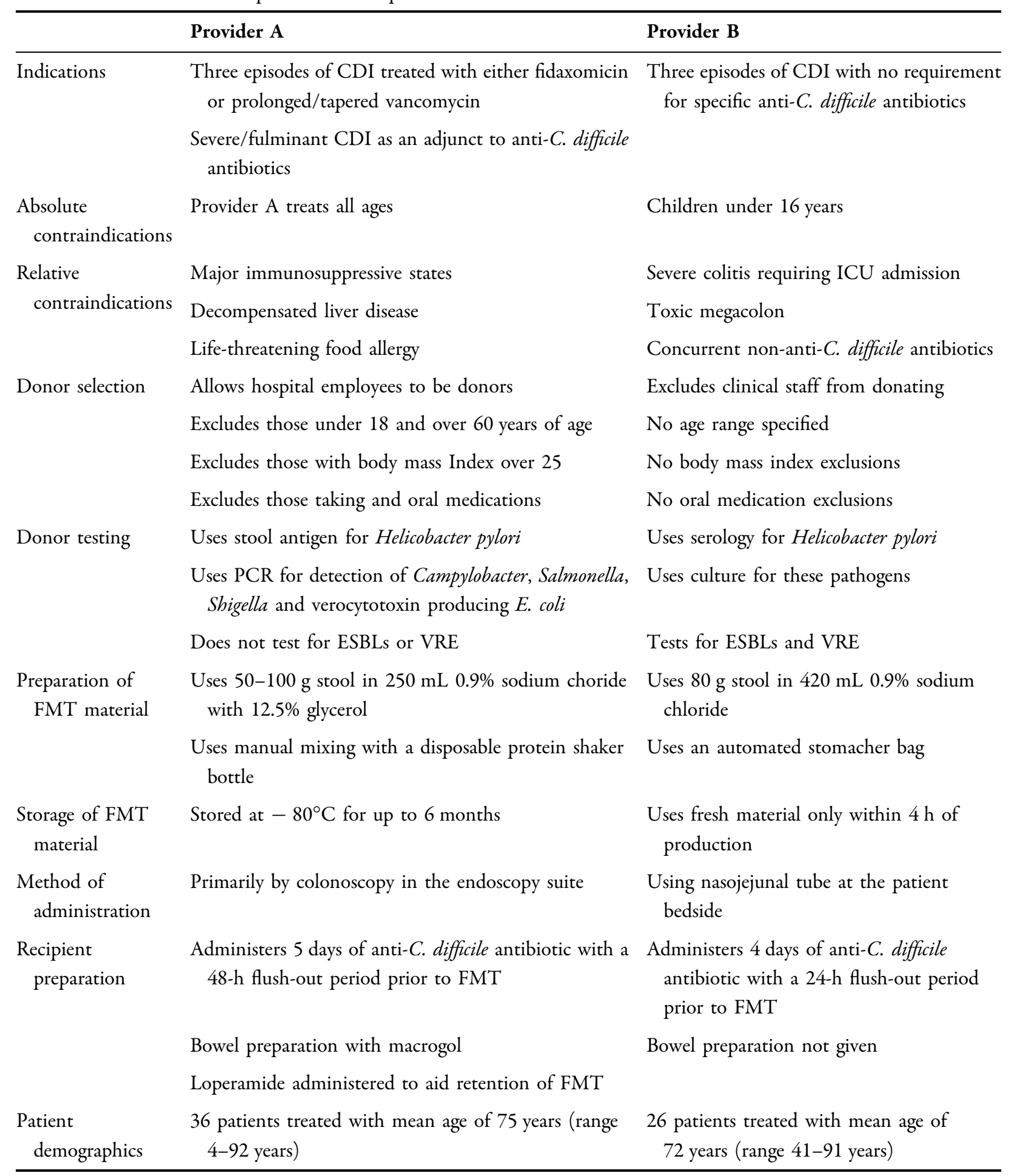


Table 2 continued

\begin{tabular}{llc}
\hline & Provider A & Provider B \\
\hline Clinical outcomes & $\begin{array}{c}\text { Primary cure rate of } 94 \%(34 / 36 \text { patients }) \\
\text { Adverse events: diarrhea, abdominal discomfort/ } \\
\text { cramping, bloating, flatulence. Two deaths-not } \\
\text { related to FMT }\end{array}$ & $\begin{array}{c}\text { Primary cure rate of } 96 \%(25 / 26 \text { patients }) \\
\text { discomfort/cramping, bloating, flatulence. }\end{array}$ \\
& $\begin{array}{c}\text { One death-aspiration pneumonia, likely } \\
\text { related to FMT }\end{array}$ \\
\hline
\end{tabular}

The mechanism by which FMT exerts its effect is not fully elucidated. A number of 'modes of action' have been proposed, including direct competition with indigenous gut microbiota, actions of secondary bile acids and immune-mediated colonization resistance [72]. Of note, a recent study which used sterile fecal filtrate to treat CDI suggests that the microorganisms within the FMT material may not be exerting any significant beneficial effect [73]. This supports the notion of other bioactive compounds in stool (e.g., various bile acids and other metabolites) as a potential mechanism of action $[74,75]$. Others suggest bacteriophages may play a significant role [76-78].

Further complicating matters in the UK setting is the classification of material prepared for FMT as a medicinal product by the Medicine and Healthcare Products Regulatory Agency (MHRA). This places a number of additional requirements on manufacturers and providers of FMT. In particular, any clinical research using FMT is likely to be classed as a Clinical Trial of an Investigational Medicinal Product and, as such, material would need to be produced according to the principles of Good Manufacturing Practice under MHRA licence. This is a significant commitment in terms of infrastructure and oversight and could be a significant barrier to the advancement of clinical research using FMT in the UK [79-82].

Ultimately, development of a defined mixture of cultured bacteria may be safer and more acceptable to patients and clinicians and allows standardization and control [83-86]. Such standardization would also allow rational design of clinical trials [87]. If such a product was produced commercially and was licensed, this could potentially facilitate more widespread adoption of FMT by healthcare providers, but is likely to take many years. In the interim, the formation of a national or regional stool banks, similar to that established in the Netherlands and other countries, could help to overcome the difficulty of access to donor material [88].

The effectiveness with which FMT has been used to treat rCDI provides hope that this therapy might also be useful in an increasing number of diseases which have been linked to a disturbed intestinal microbiota composition, including obesity and metabolic syndrome [89-91], irritable bowel syndrome, inflammatory bowel diseases [92-95] hepatic encephalopathy [96], necrotizing enterocolitis [97] and extra-intestinal disorders such as neuropsychiatric diseases [98, 99]. Recent case reports suggest that FMT may be effective in gut recolonization in patients with multi-drug resistant oganisms like ESBLs [100, 101], CPE [102, 103], and VRE [104] which currently have few treatment options.

\section{CONCLUSION}

FMT is highly efficacious for patients with multiply recurrent CDI and shows promise for a variety of other indications. Although a number of controlled trials have been reported, these tend to be small and at risk of bias. Studies are also hampered by the inherent lack of standardization involved in administering a highly variable product. Furthermore, there are 
significant technical, logistical, regulatory and safety issues with the provision of FMT to patients, both as a clinical service and in the context of clinical research. Several of these factors are perceived to be a major barrier which needs to be overcome to allow more widespread access to FMT for appropriate patient groups.

\section{ACKNOWLEDGEMENTS}

The authors would like to thank Ashley Crane, Jasmin Hastie (Eastern Pathology Alliance, Microbiology Department, Norwich) and Amita Patel (Centre for Clinical Infection and Diagnostics Research) for their assistance with FMT processing and donor coordination.

Funding. No funding or sponsorship was received for this study or publication of this article.

Authorship. All named authors meet the International Committee of Medical Journal Editors (ICMJE) criteria for authorship for this article, take responsibility for the integrity of the work as a whole, and have given their approval for this version to be published.

Disclosures. Simon D. Goldenberg, Rahul Batra, Ian Beales, Jonathan Leith Digby-Bell, Peter Miles Irving, Lee Kellingray, Arjan Narbad, and Ngozi Franslem-Elumogo have nothing to disclose.

Compliance with Ethics Guidelines. This article is based on previously conducted studies and does not contain any studies with human participants or animals performed by any of the authors.

Open Access. This article is distributed under the terms of the Creative Commons Attribution-NonCommercial 4.0 International License (http://creativecommons.org/licenses/ by-nc/4.0/), which permits any noncommercial use, distribution, and reproduction in any medium, provided you give appropriate credit to the original author(s) and the source, provide a link to the Creative Commons license, and indicate if changes were made.

\section{REFERENCES}

1. Cammarota G, Masucci L, Ianiro G, Bibbò S, Dinoi $G$, Costamagna $G$, et al. Randomised clinical trial: fecal microbiota transplantation by colonoscopy vs. Vancomycin for the treatment of recurrent Clostridium difficile infection. Aliment Pharmacol Ther. 2015;41:835-43.

2. Hota SS, Sales V, Tomlinson G, Salpeter MJ, McGeer A, Coburn B, et al. Oral vancomycin followed by fecal transplantation versus tapering oral vancomycin treatment for recurrent Clostridium difficile infection: an open-label, randomized controlled trial. Clin Infect Dis. 2016;64:265-71.

3. Jiang ZD, Ajami NJ, Petrosino JF, Jun G, Hanis CL, Shah $M$, et al. Randomised clinical trial: fecal microbiota transplantation for recurrent clostridum difficile infection-fresh, or frozen, or lyophilized microbiota from a small pool of healthy donors delivered by colonoscopy. Aliment Pharmacol Ther. 2017;45:899-908.

4. Kao D, Roach B, Silva M, Beck P, Rioux K, Kaplan GG, et al. Effect of oral capsule- vs colonoscopydelivered fecal microbiota transplantation on recurrent Clostridium difficile infection: a randomized clinical trial. JAMA. 2017;318:1985-93.

5. Kelly CR, Khoruts A, Staley C, Sadowsky MJ, Abd M, Alani M, et al. Effect of fecal microbiota transplantation on recurrence in multiply recurrent Clostridium difficile infection: a randomized trial. Ann Intern Med. 2016;165:609-16.

6. Lee $\mathrm{CH}$, Steiner T, Petrof EO, Smieja M, Roscoe D, Nematallah A, et al. Frozen vs fresh fecal microbiota transplantation and clinical resolution of diarrhea in patients with recurrent Clostridium difficile infection: a randomized clinical trial. JAMA. 2016;315:142-9.

7. van Nood E, Vrieze A, Nieuwdorp M, Fuentes S, Zoetendal EG, de Vos WM, et al. Duodenal infusion of donor feces for recurrent clostridium difficile. N Engl J Med. 2013;368:407-15.

8. Youngster I, Sauk J, Pindar C, Wilson RG, Kaplan JL, Smith $\mathrm{MB}$, et al. Fecal microbiota transplant for relapsing Clostridium difficile infection using a frozen inoculum from unrelated donors: a randomized, open-label, controlled pilot study. Clin Infect Dis. 2014;58:1515-22. 
9. National Institute for Health and Care Excellence (NICE). https://www.Nice.Org.Uk/guidance/ipg 485. Fecal Microbiota Transplant for Recurrent Clostridium difficile Infection

10. Quraishi MN, Segal J, Mullish B, McCune VL, Hawkey P, Colville A, et al. National survey of practice of fecal microbiota transplantation for Clostridium difficile infection in the UK. J Hosp Infect. 2017;95:444-5.

11. Cornely OA, Crook DW, Esposito R, Poirier A, Somero MS, Weiss $\mathrm{K}$, et al. Fidaxomicin versus vancomycin for infection with Clostridium difficile in Europe, Canada, and the USA: a double-blind, non-inferiority, randomized controlled trial. Lancet Infect Dis. 2012;12:281-9.

12. Louie TJ, Miller MA, Mullane KM, Weiss K, Lentnek A, Golan Y, et al. Fidaxomicin versus vancomycin for Clostridium difficile infection. N Engl J Med. 2011;364:422-31.

13. Zar FA, Bakkanagari SR, Moorthi KM, Davis MB. A comparison of vancomycin and metronidazole for the treatment of clostridium difficile-associated diarrhea, stratified by disease severity. Clin Infect Dis. 2007; 45:302-7.

14. Deshpande A, Pasupuleti V, Thota P, Pant C, Rolston DD, Hernandez AV, et al. Risk factors for recurrent Clostridium difficile infection: a systematic review and meta-analysis. Infect Control Hosp Epidemiol. 2015;36:452-60.

15. O'Horo JC, Jindai K, Kunzer B, Safdar N. Treatment of recurrent Clostridium difficile infection: a systematic review. Infection. 2014;42:43-59.

16. Petrella LA, Sambol SP, Cheknis A, Nagaro K, Kean $\mathrm{Y}$, Sears PS, et al. Decreased cure and increased recurrence rates for Clostridium difficile infection caused by the epidemic C. difficile BI strain. Clin Infect Dis. 2012;55:351-7.

17. Goldenberg SD, Brown S, Edwards L, Gnanarajah D, Howard P, Jenkins D, et al. The impact of the introduction of fidaxomicin on the management of Clostridium difficile infection in seven NHS secondary care hospitals in england: a series of local service evaluations. Eur J Clin Microbiol Infect Dis. 2016;35:251-9.

18. Maxwell-Scott HG, Goldenberg SD. Existing and investigational therapies for the treatment of Clostridium difficile infection: A focus on narrow spectrum, microbiota-sparing agents. Med Mal Infect. 2018;48:1-9.

19. Guery B, Menichetti F, Veli-Jukka Anttila, Adomakoh N, Aguado JM, Bisnauthsing $\mathrm{K}$, et al. Extended-pulsed fidaxomicin versus vancomycin for Clostridium difficile infection in patients 60 years and older (EXTEND): a randomized, controlled, open-label, phase $3 \mathrm{~b} / 4$ trial. Lancet Infect Dis. 2017. https://doi.org/10.1016/s1473-3099(17) 30751-X.

20. Wilcox MH, Gerding DN, Poxton IR, Kelly C, Nathan R, Birch T, et al. Bezlotoxumab for prevention of recurrent Clostridium difficile infection. N Engl J Med. 2017;376:305-17.

21. Bezlotoxumab Markham A. First global approval. Drugs. 2016;76:1793-8.

22. Jalanka J, Mattila E, Jouhten H, Hartman J, de Vos WM, Arkkila P, Satokari R. Long-term effects on luminal and mucosal microbiota and commonly acquired taxa in fecal microbiota transplantation for recurrent Clostridium difficile infection. BMC Med. 2016;14:155.

23. Lagier JC. Fecal microbiota transplantation: from practice to legislation before considering industrialization. Clin Microbiol Infect. 2014;20:1112-8.

24. Debast SB, Bauer MP, Kuijper EJ. European Society of Clinical Microbiology and Infectious Diseases. European society of clinical microbiology and infectious diseases: update of the treatment guidance document for Clostridium difficile infection. Clin Microbiol Infect. 2014;20(Suppl 2):1-26.

25. Kump PK, Krause R, Steininger C, Gröchenig HP, Moschen A, Madl C, et al. Recommendations for the use of fecal microbiota transplantation "stool transplantation": consensus of the austrian society of gastroenterology and hepatology (ÖGGH) in cooperation with the austrian society of infectious diseases and tropical medicine. Z Gastroenterol. 2014;52:1485-92.

26. Sokol H, Galperine T, Kapel N, Bourlioux P, Seksik P, Barbut F, et al. Fecal microbiota transplantation in recurrent Clostridium difficile infection: recommendations from the french group of fecal microbiota transplantation. Dig Liver Dis. 2016;48:242-7.

27. Surawicz CM, Brandt LJ, Binion DG, Ananthakrishnan AN, Curry SR, Gilligan PH, et al. Guidelines for diagnosis, treatment, and prevention of Clostridium difficile infections. Am J Gastroenterol. 2013;108:478-98.

28. Trubiano JA, Cheng AC, Korman TM, Roder C, Campbell A, May ML, et al. Australasian society of infectious diseases updated guidelines for the management of Clostridium difficile infection in adults and children in australia and new zealand. Intern Med J. 2016;46:479-93.

29. Cammarota G, Ianiro G, Tilg H, Rajilić-Stojanović M, Kump P, Satokari R, et al. European consensus 
conference on fecal microbiota transplantation in clinical practice. Gut. 2017;66:569-80.

30. König J, Siebenhaar A, Högenauer C, Arkkila P, Nieuwdorp $M$, Norén $T$, et al. Consensus report: fecal microbiota transfer-clinical applications and procedures. Aliment Pharmacol Ther. 2017;45:222-39.

31. World Health Organisation. Melbourne declaration on $100 \%$ voluntary non-renumerated donation of blood and blood components. http://www.who.int/ worldblooddonorday/Melbourne_Declaration_VNR BD_2009.pdf?ua=1 (Accessed 23 December 2017).

32. Bakken JS, Borody T, Brandt LJ, Brill JV, Demarco DC, Franzos MA, et al. Treating Clostridium difficile infection with fecal microbiota transplantation. Clin Gastroenterol Hepatol. 2011;9:1044-9.

33. Tang G, Yin W, Liu W. Is frozen fecal microbiota transplantation as effective as fresh fecal microbiota transplantation in patients with recurrent or refractory Clostridium difficile infection: a metaanalysis? Diagn Microbiol Infect Dis. 2017;88:322-9.

34. Satokari R, Mattila E, Kainulainen V, Arkkila PE. Simple fecal preparation and efficacy of frozen inoculum in fecal microbiota transplantation for recurrent Clostridium difficile infection-an observational cohort study. Aliment Pharmacol Ther. 2015;41:46-53.

35. Hamilton MJ, Weingarden AR, Unno T, Khoruts A, Sadowsky MJ. High-throughput DNA sequence analysis reveals stable engraftment of gut microbiota following transplantation of previously frozen fecal bacteria. Gut Microbes. 2013;4:125-35.

36. Kassam Z, Lee CH, Yuan Y, Hunt RH. Fecal microbiota transplantation for Clostridium difficile infection: systematic review and meta-analysis. Am J Gastroenterol. 2013;108:500-8.

37. Quraishi MN, Widlak M, Bhala N, Moore D, Price M, Sharma N, Iqbal TH. Systematic review with metaanalysis: the efficacy of fecal microbiota transplantation for the treatment of recurrent and refractory Clostridium difficile infection. Aliment Pharmacol Ther. 2017;46:479-93.

38. Cammarota G, Ianiro G, Gasbarrini A. Fecal microbiota transplantation for the treatment of Clostridium difficile infection: a systematic review. J Clin Gastroenterol. 2014;48:693-702.

39. Drekonja D, Reich J, Gezahegn S, Greer N, Shaukat A, MacDonald R, et al. Fecal microbiota transplantation for Clostridium difficile infection: a systematic review. Ann Intern Med. 2015;162: 630-8.
40. Osman M, O’Brien K, Stoltzner Z, Ling K, Koelsch E, Dubois N, et al. Safety and efficacy of fecal microbiota transplantation for recurrent Clostridium difficile infection from an international public stool bank: results from a 2050 patient multi-center cohort. Open Forum Infect Dis. 2017;3:1.

41. Link A, Lachmund T, Schulz C, Weigt J, Malfertheiner P. Endoscopic peroral jejunal fecal microbiota transplantation. Dig Liver Dis. 2016;48:1336-9.

42. Human tissue act 2004 (chapter 30). London, UK: Office of Public Sector Information. URL: https:// www.Opsi.Gov.Uk/ACTS/acts2004/ukpga_2004003 0_en_1 [accessed 23 December 2017].

43. Human Tissue Authority Codes of Practice and Standards. https://www.hta.gov.uk/hta-codespractice-and-standards-0 (Accessed 23 December 2017).

44. Baxter M, Ahmad T, Colville A, Sheridan R. Fatal aspiration pneumonia as a complication of fecal microbiota transplant. Clin Infect Dis. 2015;61:136-7.

45. Li YT, Cai HF, Wang ZH, Xu J, Fang JY. Systematic review with meta-analysis: long-term outcomes of fecal microbiota transplantation for Clostrdium difficile infection. Aliment Pharmacol Ther. 2016;43:445-57.

46. Baxter M, Colville A. Adverse events in fecal microbiota transplant: a review of the literature. J Hosp Infect. 2016;92:117-27.

47. Agrawal M, Aroniadis OC, Brandt LJ, Kelly C, Freeman S, Surawicz C, et al. The long-term efficacy and safety of fecal microbiota transplant for recurrent, severe, and complicated Clostridium difficile infection in 146 elderly individuals. J Clin Gastroenterol. 2016;50:403-7.

48. Prior AR, Kevans D, McDowell L, Cudmore S, Fitzpatrick F. Treatment of Clostridium difficile infection: a national survey of clinician recommendations and the use of fecal microbiota transplantation. J Hosp Infect. 2017;95:438-41.

49. Porter RJ, Fogg C. Fecal microbiota transplantation for Clostridium difficile infection in the United Kingdom. Clin Microbiol Infect. 2015;21:578-82.

50. Quraishi MN, Segal J, Mullish B, McClune VM, Hawkey P, Colville A, et al. National survey of practice of fecal microbiota transplantation for Clostridium difficile infection in the UK. J Hosp Infect. 2017;95:442-6.

51. Postigo R, Kim JH. Colonoscopic versus nasogastric fecal transplantation for the treatment of 
Clostridium difficile infection: a review and pooled analysis. Infection. 2012;40:643-8.

52. Furuya-Kanamori L, Doi SA, Paterson DL, Helms SK, Yakob L, McKenzie SJ, et al. Upper versus lower gastrointestinal delivery for transplantation of fecal microbiota in recurrent or refractory Clostridium difficile infection: a collaborative analysis of individual patient data from 14 studies. J Clin Gastroenterol. 2017;51:145-50.

53. Youngster I, Mahabamunuge J, Systrom HK, Sauk J, Khalili H, Levin J, et al. Oral, frozen fecal microbiota transplant (FMT) capsules for recurrent Clostridium difficile infection. BMC Med. 2016;14:134.

54. Hirsch BE, Saraiya N, Poeth K, Schwartz RM, Epstein $\mathrm{ME}$, Honig G. Effectiveness of fecal-derived microbiota transfer using orally administered capsules for recurrent Clostridium difficile infection. BMC Infect Dis. 2015;15:191.

55. Youngster I, Russell GH, Pindar C, Ziv-Baran T, Sauk J, Hohmann EL. Oral, capsulized, frozen fecal microbiota transplantation for relapsing Clostridium difficile infection. JAMA. 2014;312:1772-8.

56. Hecker MT, Obrenovich ME, Cadnum JL, Jencson AL, Jain AK, Ho E, Donskey CJ. Fecal microbiota transplantation by freeze-dried oral capsules for recurrent Clostridium difficile infection. Open Forum Infect Dis. 2016;3:ofw091.

57. Staley C, Hamilton MJ, Vaughn BP, Graiziger CT, Newman KM, Kabage AJ, et al. Successful resolution of recurrent Clostridium difficile infection using freeze-dried, encapsulated fecal microbiota; pragmatic cohort study. Am J Gastroenterol. 2017;112:940-7.

58. Kelly CR, de Leon L, Jasutkar N. Fecal microbiota transplantation for relapsing Clostridium difficile infection in 26 patients: methodology and results. J Clin Gastroenterol. 2012;46:145-9.

59. Brandt LJ, Aroniadis OC, Mellow M, Kanatzar A, Kelly C, Park T, et al. Long-term follow-up of colonoscopic fecal microbiota transplant for recurrent Clostridium difficile infection. Am J Gastroenterol. 2012;107:1079-87.

60. Pathak R, Enuh HA, Patel A, Wickremesinghe P. Treatment of relapsing Clostridium difficile infection using fecal microbiota transplantation. Clin Exp Gastroenterol. 2013;7:1-6.

61. Patel NC, Griesbach CL, DiBaise JK, Orenstein R. Fecal microbiota transplant for recurrent Clostridium difficile infection: mayo clinic in arizona experience. Mayo Clin Proc. 2013;88:799-805.
62. MacConnachie AA, Fox R, Kennedy DR, Seaton RA. Fecal transplant for recurrent clostridium difficileassociated diarrhea: a UK case series. QJM. 2009;102:781-4.

63. Ray A, Smith R, Breaux J. Fecal microbiota transplantation for Clostridium difficile infection: the ochsner experience. Ochsner J. 2014;14:538-44.

64. Kelly CR, Ihunnah C, Fischer M, Khoruts A, Surawicz C, Afzali A, et al. Fecal microbiota transplant for treatment of Clostridium difficile infection in immunocompromised patients. Am J Gastroenterol. 2014;109:1065-71.

65. Garborg K, Waagsbø B, Stallemo A, Matre J, Sundøy A. Results of fecal donor instillation therapy for recurrent clostridium difficile-associated diarrhea. Scand J Infect Dis. 2010;42:857-61.

66. Hamilton MJ, Weingarden AR, Sadowsky MJ, Khoruts A. Standardized frozen preparation for transplantation of fecal microbiota for recurrent Clostridium difficile infection. Am J Gastroenterol. 2012;107:761-7.

67. Lee CH, Belanger JE, Kassam Z, Smieja M, Higgins D, Broukhanski G, Kim PT. The outcome and longterm follow-up of 94 patients with recurrent and refractory Clostridium difficile infection using single to multiple fecal microbiota transplantation via retention enema. Eur J Clin Microbiol Infect Dis. 2014;33:1425-8.

68. Rubin TA, Gessert CE, Aas J, Bakken JS. Fecal microbiome transplantation for recurrent Clostridium difficile infection: report on a case series. Anaerobe. 2013;19:22-6.

69. Yoon SS, Brandt LJ. Treatment of refractory/recurrent C. Difficile-associated disease by donated stool transplanted via colonoscopy: a case series of 12 patients. J Clin Gastroenterol. 2010;44:562-6.

70. Zainah H, Hassan M, Shiekh-Sroujieh L, Hassan S, Alangaden G, Ramesh M. Intestinal microbiota transplantation, a simple and effective treatment for severe and refractory Clostridium difficile infection. Dig Dis Sci. 2015;60:181-5.

71. Abujamel T, Cadnum JL, Jury LA, Sunkesula VC, Kundrapu S, Jump RL, et al. Defining the vulnerable period for re-establishment of Clostridium difficile colonization after treatment of C. Difficile infection with oral vancomycin or metronidazole. PLOS ONE. 2013;8:e76269.

72. Khoruts A, Sadowsky MJ. Understanding the mechanisms of fecal microbiota transplantation. Nat Rev Gastroenterol Hepatol. 2016;13:508-16. 
73. Ott SJ, Waetzig GH, Rehman A, Moltzau-Anderson J, Bharti R, Grasis JA, et al. Efficacy of sterile fecal filtrate transfer for treating patients with Clostridium difficile infection. Gastroenterology. 2017;152(799-811):e7.

74. Bojanova DP, Bordenstein SR. Fecal transplants: what is being transferred? PLoS Biol. 2016;14:e1002503.

75. Weingarden AR, Dosa PI, DeWinter E, Steer CJ, Shaughnessy MK, Johnson JR, et al. Changes in colonic bile acid composition following fecal microbiota transplantation are sufficient to control Clostridium difficile germination and growth. PLoS ONE. 2016;11:e0147210.

76. Zuo T, Wong SH, Lam K, Lui R, Cheung K, Tang W, et al. Bacteriophage transfer during fecal microbiota transplantation in Clostridium difficile infection is associated with treatment outcome. Gut. 2017. https://doi.org/10.1136/gutjnl-2017-313952 [Epub ahead of print].

77. Rea MC, Alemayehu D, Ross RP, Hill C. Gut solutions to a gut problem: bacteriocins, probiotics and bacteriophage for control of Clostridium difficile infection. J Med Microbiol. 2013;62(Pt 9):1369-78.

78. Moelling K, Broecker F. Fecal microbiota transplantation to fight Clostridium difficile infections and other intestinal diseases. Bacteriophage. 2016;6:e1251380.

79. Goldenberg SD. Fecal microbiota transplantation for recurrent Clostridium difficile infection and beyond: risks and regulation. J Hosp Infect. 2016;92(2):115-6.

80. Hecht GA, Blaser MJ, Gordon J, Kaplan LM, Knight $\mathrm{R}$, Laine $\mathrm{L}$, et al. What is the value of a food and drug administration investigational new drug application for fecal microbiota transplantation to treat Clostridium difficile Infection? Clin Gastroenterol Hepatol. 2014;12:289-91.

81. Kelly CR, Kunde SS, Khoruts A. Guidance on preparing an investigational new drug application for fecal microbiota transplantation studies. Clin Gastroenterol Hepatol. 2014;12:283-8.

82. Moore T, Rodriguez A, Bakken JS. Fecal microbiota transplantation: a practical update for the infectious disease specialist. Clin Infect Dis. 2014;58:541-5.

83. Allen-Vercoe E, Petrof EO. Bringing the gut microbiota into focus through microbial culture: recent progress and future perspective. Curr Opin Microbiol. 2013;16:625-9.
84. Petrof EO, Gloor GB, Vanner SJ, Weese SJ, Carter D, Daigneault $\mathrm{MC}$, et al. Stool substitute transplant therapy for the eradication of Clostridium difficile infection: 'RePOOPulating' the gut. Microbiome. 2013;9(1):3.

85. Petrof EO, Khoruts A. From stool transplants to next-generation microbiota therapeutics. Gastroenterology. 2014;146:1573-82.

86. Adamu BO, Lawley TD. Bacteriotherapy for the treatment of intestinal dysbiosis caused by Clostridium difficile infection. Curr Opin Microbiol. 2013;16:596-601.

87. Olesen SW, Gurry T, Alm EJ. Designing fecal microbiota transplant trials that account for differences in donor stool efficacy. Stat Methods Med Res. 2017. https://doi.org/10.1177/0962280216688502.

88. Terveer EM, van Beurden YH, Goorhuis A, Seegers JFML, Bauer MP, van Nood E, et al. How to: establish and run a stool bank. Clin Microbiol Infect. 2017;23:924-30.

89. Torres-Fuentes C, Schellekens H, Dinan TG, Cryan JF. The microbiota-gut-brain axis in obesity. Lancet Gastroenterol Hepatol. 2017;2:747-56.

90. Marotz CA, Zarrinpar A. Treating obesity and metabolic syndrome with fecal microbiota transplantation. Yale J Biol Med. 2016;89:383-8.

91. Kootte RS, Levin E, Salojärvi J, Smits LP, Hartstra AV, Udayappan SD, et al. Improvement of insulin sensitivity after lean donor feces in metabolic syndrome is driven by baseline intestinal microbiota composition. Cell Metab. 2017;26(611-619):e6.

92. Narula N, Kassam Z, Yuan Y, Colombel JF, Ponsioen C, Reinisch W, Moayyedi P. Systematic review and meta-analysis: fecal microbiota transplantation for treatment of active ulcerative colitis. Inflamm Bowel Dis. 2017;23:1702-9.

93. Nishida A, Imaeda H, Ohno M, Inatomi O, Bamba S, Sugimoto M, Andoh A. Efficacy and safety of single fecal microbiota transplantation for japanese patients with mild to moderately active ulcerative colitis. J Gastroenterol. 2017;52:476-82.

94. Costello SP, Soo W, Bryant RV, Jairath V, Hart AL, Andrews JM. Systematic review with meta-analysis: fecal microbiota transplantation for the induction of remission for active ulcerative colitis. Aliment Pharmacol Ther. 2017;46:213-24.

95. Paramsothy S, Paramsothy R, Rubin DT, Kamm MA, Kaakoush NO, Mitchell HM, Castaño-Rodríguez N. Fecal microbiota transplantation for inflammatory bowel disease: a systematic review and meta-analysis. J Crohns Colitis. 2017;11:1180-99. 
96. Bajaj JS, Kassam Z, Fagan A, Gavis EA, Liu E, Cox IJ, et al. Fecal microbiota transplant from a rational stool donor improves hepatic encephalopathy: a randomized clinical trial. Hepatology. 2017;66:1727-38.

97. Vongbhavit K, Underwood MA. Prevention of necrotizing enterocolitis through manipulation of the intestinal microbiota of the premature infant. Clin Ther. 2016;38:716-32.

98. Quigley EMM. Microbiota-Brain-Gut axis and neurodegenerative diseases. Curr Neurol Neurosci Rep. 2017;17:94.

99. Kang DW, Adams JB, Gregory AC, Borody T, Chittick L, Fasano A, et al. Microbiota transfer therapy alters gut ecosystem and improves gastrointestinal and autism symptoms: an open-label study. Microbiome. 2017;5:10.

100. Biliński J, Grzesiowski P, Muszyński J, Wróblewska M, Mądry K, Robak K, et al. Fecal Microbiota Transplantation Inhibits Multidrug-Resistant Gut Pathogens: Preliminary Report Performed in an Immunocompromised Host. Arch Immunol Ther Exp. 2016;64:255-8.
101. Millan B, Park H, Hotte N, Mathieu O, Burguiere P, Tompkins TA, et al. Fecal microbial transplants reduce antibiotic-resistant genes in patients with recurrent Clostridium difficile infection. Clin Infect Dis. 2016;62:1479-86.

102. Davido B, Batista R, Michelon H, Lepainteur $M$, Bouchand F, Lepeule $\mathrm{R}$, et al. Is fecal microbiota transplantation an option to eradicate highly drugresistant enteric bacteria carriage? J Hosp Infect. 2017;95:433-7.

103. Crum-Cianflone NF, Sullivan E, Ballon-Landa G. Fecal microbiota transplantation and successful resolution of multidrug-resistant-organism colonization. J Clin Microbiol. 2015;53:1986-9.

104. Stripling J, Kumar R, Baddley JW, Nellore A, Dixon $\mathrm{P}$, Howard $\mathrm{D}$, et al. Loss of vancomycin-resistant enterococcus fecal dominance in an organ transplant patient with Clostridium difficile colitis after fecal microbiota transplant. Open Forum Infect Dis. 2015;2:ofv078. 